\title{
Meta-analysis of haplotype-association studies: comparison of methods and empirical evaluation of the literature
}

Pantelis G Bagos

\begin{abstract}
Background: Meta-analysis is a popular methodology in several fields of medical research, including genetic association studies. However, the methods used for meta-analysis of association studies that report haplotypes have not been studied in detail. In this work, methods for performing meta-analysis of haplotype association studies are summarized, compared and presented in a unified framework along with an empirical evaluation of the literature.

Results: We present multivariate methods that use summary-based data as well as methods that use binary and count data in a generalized linear mixed model framework (logistic regression, multinomial regression and Poisson regression). The methods presented here avoid the inflation of the type I error rate that could be the result of the traditional approach of comparing a haplotype against the remaining ones, whereas, they can be fitted using standard software. Moreover, formal global tests are presented for assessing the statistical significance of the overall association. Although the methods presented here assume that the haplotypes are directly observed, they can be easily extended to allow for such an uncertainty by weighting the haplotypes by their probability.

Conclusions: An empirical evaluation of the published literature and a comparison against the meta-analyses that use single nucleotide polymorphisms, suggests that the studies reporting meta-analysis of haplotypes contain approximately half of the included studies and produce significant results twice more often. We show that this excess of statistically significant results, stems from the sub-optimal method of analysis used and, in approximately half of the cases, the statistical significance is refuted if the data are properly re-analyzed. Illustrative examples of code are given in Stata and it is anticipated that the methods developed in this work will be widely applied in the meta-analysis of haplotype association studies.
\end{abstract}

\section{Background}

The continuously increasing number of published genedisease association studies made imperative the need of collecting and synthesizing the available data $[1,2]$. The statistical procedure with which data from multiple studies are synthesized is known as meta-analysis [3-5]. In meta-analysis, a set of original studies is synthesized and the potential heterogeneity is explored using formal statistical methods $[3,4,6,7]$. In the medical literature, meta-analysis was initially applied in the field of randomized clinical trials $[8,9]$, but nowadays it is considered a valuable tool for the combination of observational

Correspondence: pbagos@ucg.gr

Department of Computer Science and Biomedical Informatics, University of Central Greece, Papasiopoulou 2-4, Lamia 35100, Greece studies [10], as well as for genetic association studies for which specialized methodology has been developed [5,11-18].

Most of the genetic association studies (and hence the meta-analyses derived from them) are performed using single markers, usually Single Nucleotide Polymorphisms (SNPs). However, the SNP that is under investigation is not always the true susceptibility allele. Instead, it may be a polymorphism which is in Linkage Disequilibrium (LD) with the unknown disease-causing locus [19]. In such cases, the single marker tests may be underpowered, depending on the degree of LD and the allele frequencies [20]. Haplotypes, which are the combination of closely linked alleles on a chromosome, are therefore important in the study of the genetic basis of
C Biomed Central

(c) 2011 Bagos; licensee BioMed Central Ltd. This is an Open Access article distributed under the terms of the Creative Commons Attribution License (http://creativecommons.org/licenses/by/2.0), which permits unrestricted use, distribution, and reproduction in any medium, provided the original work is properly cited. 
diseases and thus, they are extensively used [21,22]. The importance of studying haplotypes ranges from elucidating the exact biological role played by neighbouring amino-acids on the protein structure, to providing information about ancient ancestral chromosome segments that harbour alleles influencing human traits [23]. Moreover, haplotype association methods are considered to be more powerful compared to single marker analyses $[24,25]$, even though this is questioned by some researchers [26].

A major problem in haplotype analyses is that in order for the analysis to be performed we need to reconstruct or infer the haplotypes, usually with an approach based on missing data imputation [27-29]. This uncertainty in imputing the haplotypes poses some problems in the analysis [30] that are to be discussed later in this work. Nevertheless, studies that investigate the association of haplotypes with diseases are increasingly being published (Figure 1), with an even more increasing rate after 2003, when the HapMap project was initiated [31]. This exponential increase follows the general pattern of gene-disease association studies $[1,2,32]$ and naturally, the obvious extension would be to use meta-analysis in order to increase the power of individual studies and to resolve the reasons of heterogeneity and inconsistency.

This work has two primary goals. First, to perform a detailed literature search and an empirical evaluation of the published studies that report meta-analyses of haplotype associations; and second, to present a concise overview of the statistical methods that could and should be used in such meta-analyses. These two important issues were not previously studied in the literature and the

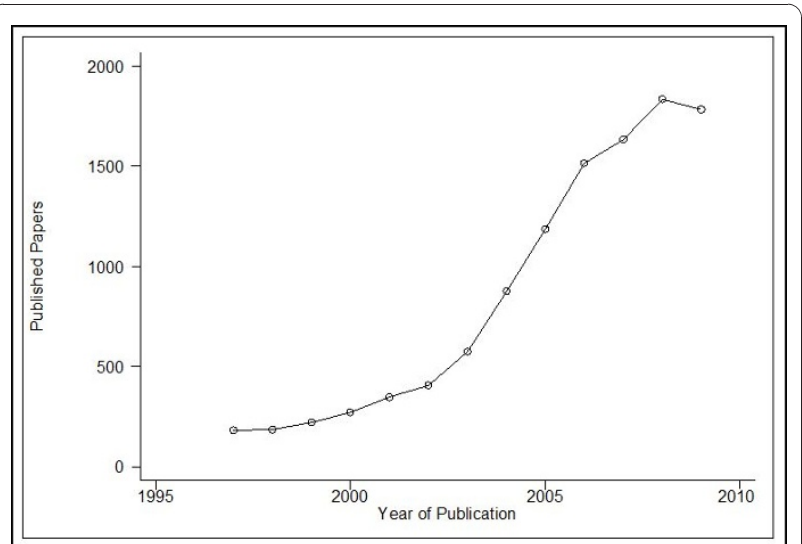

Figure $1 \mathrm{~A}$ graphical representation of the increasing number of published haplotype-association studies. A search was performed in Pubmed using the terms "haplotype" and "association" from 1997 to 2009. Even though the reference list may include review articles, methodological papers or even irrelevant works, the trend is obvious, especially after 2003 when the HapMap project was presented. The search was conducted during December 2009 and thus the count for 2009 may be an underestimate. findings are interesting. Even though the methods presented in this work could be derived in a straightforward manner from extending previous works on multivariate meta-analysis [33-37], the majority of the published meta-analyses did not use optimal methods for analyzing the data. Moreover, in several circumstances the results of some studies are shown to be severely flawed. The manuscript is organized as follows: Initially, the commonly used methods for haplotype analysis for a single study are reviewed in order to establish notation. Afterwards, the methods of meta-analysis are presented. In particular, we present the standard method of univariate meta-analysis and its limitations, which leads to a more powerful multivariate approach based on summary-data. Accordingly, a general framework based on generalized linear mixed models (GLMMs) is presented and the approaches based on logistic regression, multinomial logistic regression and Poisson regression are discussed. We also discuss continuous traits and details of the implementation of the models. Finally, we present the results of the empirical evaluation of the literature and compare the results reported in these analyses with the ones obtained using the methods developed here.

\section{Methods}

\section{Methods for haplotype association}

Let's assume we have $n$ biallelic markers that form a haplotype. If the alleles in position $m(m=1,2 \ldots n)$ are denoted by $A^{m}$ and $B^{m}$ the possible haplotypes would be $r=2^{n}$. In a case-control study, a cross-tabulation of haplotypes by disease status, that ignores the individuals and counts only the total number of haplotypes observed in the analysis, would result in data arranged in the form of a $2 \times r$ contingency table (Table 1 ). This cross-tabulation is somehow simplistic since it assumes a multiplicative (co-dominant) model of inheritance [38]. However, it is the most commonly reported form of haplotype data and thus, it is more suitable for metaanalysis of published studies as we will discuss later. Assuming a binomial sampling scheme where fixed numbers of cases and controls are sampled independently, we can model the structure of the table using logistic regression methods where the status (case/

Table 1 Cross-tabulation of haplotypes by disease status

\begin{tabular}{lll}
\hline Haplotype $\left(\boldsymbol{z}_{\boldsymbol{j}}\right)$ & Cases $(\boldsymbol{y}=\mathbf{1})$ & Controls $(\boldsymbol{y}=\mathbf{0})$ \\
\hline 1 & 89 & 183 \\
2 & 14 & 26 \\
3 & 24 & 22 \\
4 & 3 & 3 \\
\hline
\end{tabular}

The haplotype data obtained in a case-control study on 182 caucasian women concerning the association of p53 haplotypes with breast cancer [108]. The data are presented in the form described by Wallenstein and coworkers [38]. 
control) is the dependent variable and the haplotypes are treated as covariates. This corresponds to the socalled "prospective likelihood", the likelihood based on the probability of the disease given the exposure. Thus, we denote by $\pi_{j}=P\left(y_{j}=1\right)$ the underlying risk (i.e. the probability of being a case) of a person carrying a single copy of the $j^{\text {th }}$ haplotype. A reasonable choice would be to consider the most common haplotype (i.e. $h_{1}$ ) as the reference category and create $r$-1 dummy variables taking values $z_{j}=1$ for haplotype $j$ and 0 otherwise. This model can be formulated as:

$$
\operatorname{logit}\left(\pi_{j}\right)=\operatorname{logit}\left[P\left(y_{j}=1 \mid j\right)\right]=\beta_{0}+\sum_{j=2}^{r} \beta_{j} z_{j}
$$

This model was proposed initially by Wallenstein and co-workers and as we already mentioned, assumes a multiplicative genetic model of inheritance [38]. Moreover, the haplotypes are assumed known quantities, which may not always be the case (see below).

Alternatively, assuming a multinomial sampling scheme where the total sample size is considered fixed, a multinomial logistic regression model would be appropriate, where the different haplotypes would be the dependent variables. This corresponds to the wellknown "retrospective likelihood" (i.e. the likelihood based on the probability of exposure given disease status) applicable in case control studies. In this case, the haplotypes are treated as dependent variables and the case/control status as the predictor in a multinomial (polytomous or polychotomous) logistic regression [39]:

$$
p_{j}=P\left(j \mid \gamma_{j}\right)=\frac{\exp \left(\alpha_{j}+\beta_{j} y_{j}\right)}{\sum_{j=1}^{r} \exp \left(\alpha_{j}+\beta_{j} y_{j}\right)}
$$

By observing that the linear predictor becomes:

$$
U_{j}=\log \left(\frac{p_{j}}{p_{1}}\right)=a_{j}+\beta_{j} y_{j}, j=1,2, \ldots, r
$$

it is easy to understand that the $\beta_{j}$ coefficients obtained by fitting the model are estimates of the logOdds Ratios (i.e. for comparing $h_{j}$ vs. $h_{1}$ ) in equivalence to the respective coefficients of the model in Eq. (1). Obviously, $\beta_{1}=0$ for identifiability since haplotype $j=1$ (i.e. $h_{1}$ ) is used as the reference category. The particular model was first used for haplotype analysis by Chen and Kao [40].

Lastly, assuming that the observed counts are realizations of a Poisson random variable, one can fit log-linear models (Poisson regression), where the dependent variable is the counts and thus, the studies, the type of haplotypes and the case/control status are treated as independent variables. Log-linear models are widely used for haplotype analysis, for instance, for detecting LD [41,42] and for haplotype-disease association [43,44]. This model can be formulated in terms of a Poisson regression model in the context of generalized linear models, as:

$$
\log \left(n_{j}\right)=\mu_{0}+\beta_{0} y_{j}+\sum_{j=2}^{r} a_{j} z_{j}+\sum_{j=2}^{r} \beta_{j} z_{j} y_{j}
$$

This is the standard saturated model for describing the $2 \times r$ contingency table of haplotypes by disease. The $\beta_{j}$ 's are the coefficients that correspond to the haplotype by disease interaction and are equivalent to those obtained by fitting the models in Eq. (1) and (2). It is easily verified that the coefficients $\alpha$ 's and $\beta$ 's are identical across the three models. The overall hypothesis for association $(\boldsymbol{\beta}=\mathbf{0})$ can be tested by performing a multivariate Wald test using the estimated covariance matrix, $\operatorname{cov}(\boldsymbol{\beta})$. Then, the test statistic (score) $U=\boldsymbol{\beta}^{\prime} \operatorname{cov}(\boldsymbol{\beta})^{-1} \boldsymbol{\beta}$, will have asymptotically a $\chi^{2}$ distribution on $r$-1 degrees of freedom. Alternatively, a likelihood ratio test comparing the saturated model against the model with no interaction can be performed. Similar tests can be performed for the models in Eq. (1) and (2).

Whatever the assumed sampling scheme that gave rise to the data of Table 1 may be, it is well known that the results of fitting each one of the three models are nearly identical [45]. For instance, it has been shown that maximum likelihood estimates obtained from the "retrospective" likelihood are the same as those obtained from the "prospective" likelihood [46,47]. The equivalence of logistic regression and Poisson modelling has been also exploited in the past for deriving methods for detecting gene-environment interactions [48].

The methods discussed above are simple applications of the generalized linear model extending the analysis of single markers to haplotypes and assume that, i) the haplotype risk follows a multiplicative model of inheritance, ii), the haplotype phase is known and, iii) the population is in Hardy-Weinberg Equilibrium (HWE). The genetic model of inheritance can be handled simply by using in the analysis the so-called haplo-genotypes or diplotypes, instead of the genotypes. This is easily performed with all the previously presented methods by using the pairwise combinations of haplotypes $\left(h_{1} h_{1}\right.$, $h_{1} h_{2}$ and so on). In case-control association studies, however, with the exception of some cases where direct genotyping of the haplotypes is applicable (i.e. [38]), the haplotypes (and the haplo-genotypes) are usually not known, but are inferred from the data using statistical methods for missing data, usually with an EM or EM- 
like algorithm [27-29]. Thus, treating them as known quantities has been shown to be problematic [30]. More advanced methods have been developed in order to account for these limitations, for instance weighting the haplotypes by their probability $[49,50]$. Score methods based on the prospective likelihood [51] or the retrospective likelihood [52], have also been developed, as well as methods for allowing for gene-environment interaction [53]. A comparison of methods has shown that the approaches are roughly comparable when the haplotype effect on disease odds follows a multiplicative model. However, for dominant and recessive models, the retrospective-likelihood method has increased efficiency with respect to the prospective methods [54]. Graphical models have been proposed by Thomas [55] and log-linear models by Baker [56]. Lin and co-workers extended the previously presented methods by including various sampling schemes in a unified framework [57].

Even though a large body of the genetic epidemiology literature is dedicated to such methods, their application in meta-analysis is problematic since in most cases the original data are not available to the analyst. Thus, in the following sections where the methods for metaanalysis are summarized we also assume that the haplotypes are known. An extension when the posterior probabilities of haplotypes are given from the output of the haplotype inference software would then be straightforward.

\section{Methods for meta-analysis of haplotype association}

In this section the methods for meta-analysis are presented. Initially we will discuss simple methods using summary data, whereas in the next sub-section more advanced methods that use generalized linear models on grouped or Individual Patients Data (IPD) are presented.

\section{Meta-analysis using summary-data}

A commonly used approach that is based on traditional methods and uses solely summary data is to consider separately the effect of the $j^{\text {th }}$ haplotype against the $j-1$ remaining ones. That is, for each study $i(i=1,2, \ldots, k)$ we will compute a log-Odds Ratio (logOR):

$$
y_{i}=\log O R_{i}=\log \left(\frac{n_{i j 1} n_{i c 0}}{n_{i j 0} n_{i c 1}}\right)
$$

with an asymptotic variance given by:

$$
\operatorname{var}\left(y_{i}\right)=s_{i}^{2}=\frac{1}{n_{i j 1}}+\frac{1}{n_{i c 0}}+\frac{1}{n_{i j 0}}+\frac{1}{n_{i c 1}}
$$

In this notation, $n_{i c 0}$ an $n_{i c 1}$, are the counts of the remaining haplotypes (excluding haplotype $j$ ) for controls and cases of the $i^{\text {th }}$ study respectively, given by:

$$
\begin{aligned}
& n_{i c 0}=\sum_{j^{\prime}=1}^{r} n_{i j^{\prime} 0}-n_{i j 0}=\sum_{j^{\prime}=1 \mid j^{\prime} \neq j}^{r} n_{i j^{\prime} 0} \\
& n_{i c 1}=\sum_{j^{\prime}=1}^{r} n_{i j^{\prime} 1}-n_{i j 1}=\sum_{j^{\prime}=1 \mid j^{\prime} \neq j}^{r} n_{i j^{\prime} 1}
\end{aligned}
$$

In a standard univariate random-effects model we assume that the logarithm of the OR of each study $i$, is distributed normally as:

$$
\gamma_{i}-N\left(\beta, s_{i}^{2}+\tau^{2}\right)
$$

Thus, the combined logarithm of the Odds Ratio $(\log O R)$ would be given by:

$$
\hat{\beta}=\sum_{i=1}^{k} w_{i} \beta_{i} / \sum_{i=1}^{k} w_{i}, \text { with } w_{i}=1 /\left(s_{i}^{2}+\tau^{2}\right)(9)
$$

The between-studies variance $\left(\tau^{2}\right)$, could be easily computed by the non-iterative method of moments proposed by Dersimonian and Laird [58], even though there are several alternatives that use iterative procedures (i.e. Maximum Likelihood (ML) or Restricted Maximum Likelihood (REML) [33]). Apparently, by setting $\tau^{2}=0$ in Eq. (9) corresponds to the well known fixed-effects estimator with inverse variance weights.

The particular approach is very easily implemented, intuitive and it can be performed in a standard univariate meta-analysis framework. In the results section we will see that several already published meta-analyses used this method. However, the method has some drawbacks. The most important is that it is prone to an increased type I error rate due to multiple comparisons. Multiple comparisons constitute an important problem in haplotype analysis, especially as the number of haplotypes increases $[59,60]$. The model implied by Eqs. (5) (8), is conceptually similar to collapsing the genotypes in a single-marker analysis, an approach that has been shown to increase the power as well the type I error rate [61]. Thus, the particular approach can be justified, only when there is strong prior knowledge concerning a particular haplotype and this haplotype is the only one that is being tested.

To overcome the multiple comparisons problem, a straightforward alternative would be to extend the model in a multivariate framework modelling simultaneously the logORs derived from comparing haplotypes $j=2,3, \ldots, r$ against a reference haplotype $(j=1)$. Following the general framework for multivariate meta-analysis $[37,62]$, we denote by $\mathbf{y}_{i}$ the vector containing the $r-1$ 
different estimates, and by $\beta$, the vector of the overall means given by:

$$
\mathbf{y}_{i}=\left(\begin{array}{l}
y_{2 i} \\
y_{3 i} \\
\ldots \\
y_{r i}
\end{array}\right) \text { and } \boldsymbol{\beta}=\left(\begin{array}{l}
\beta_{2} \\
\beta_{3} \\
\ldots \\
\beta_{r}
\end{array}\right)
$$

These logORs similarly to Eq. (5) will be given by:

$$
y_{j i}=\log O R_{j i}=\log \left(\frac{n_{i j 1} n_{i 10}}{n_{i j 0} n_{i 11}}\right)
$$

with an asymptotic variance given by:

$$
\operatorname{var}\left(y_{j i}\right)=s_{j i}^{2}=\frac{1}{n_{i j 1}}+\frac{1}{n_{i 10}}+\frac{1}{n_{i j 0}}+\frac{1}{n_{i 11}}
$$

In the multivariate random-effects meta-analysis, we assume that $\mathbf{y}_{i}$ is distributed following a multivariate normal distribution around the true means $\beta$, according to the marginal model:

$$
\mathbf{y}_{i} \sim \operatorname{MVN}\left(\boldsymbol{\beta}, \boldsymbol{\Sigma}+\mathbf{C}_{i}\right)
$$

In the above model, we denote by $\mathbf{C}_{i}$ the within-studies covariance matrix:

$$
\mathrm{C}_{i}=\left(\begin{array}{cccc}
s_{2 i}^{2} & \rho_{W 23} s_{2 i} s_{3 i} & \ldots & \rho_{W 2 r} s_{2 i} s_{r i} \\
\rho_{W 23} s_{2 i} s_{3 i} & s_{3 i}^{2} & \ldots & \rho_{W 3 r} s_{3 i} s_{r i} \\
\ldots & \ldots & \ldots & \ldots \\
\rho_{W 2 r} s_{2 i} s_{r i} & \rho_{W 3 r} s_{3 i} s_{r i} & \ldots & s_{r i}^{2}
\end{array}\right)
$$

and by $\boldsymbol{\Sigma}$ the between-studies covariance matrix, given by:

$$
\Sigma=\left(\begin{array}{cccc}
\tau_{2}^{2} & \rho_{B 23} \tau_{2} \tau_{3} & \ldots & \rho_{B r 2} \tau_{2} \tau_{r} \\
\rho_{B 23} \tau_{2} \tau_{3} & \tau_{3}^{2} & \ldots & \rho_{B r 3} \tau_{3} \tau_{r} \\
\ldots & \ldots & \ldots & \ldots \\
\rho_{B r 2} \tau_{2} \tau_{r} & \rho_{B r 3} \tau_{3} \tau_{r} & \ldots & \tau_{r}^{2}
\end{array}\right)
$$

The diagonal elements of $\mathbf{C}_{i}$ are the study-specific estimates of the variance that are assumed known, whereas the off-diagonal elements correspond to the pairwise within-studies covariances, for instance $\rho_{w 23} \mathrm{~S}_{2 i} \mathrm{~S}_{3 i}=\operatorname{cov}\left(y_{2 i}\right.$, $\left.y_{3 i}\right)$. Since the $\log$ ORs derived for each haplotype are compared against the same reference category, their pairwise covariances will be given [12], by:

$$
\operatorname{cov}\left(y_{j i}, y_{j^{\prime} i}\right)=\frac{1}{n_{i 10}}+\frac{1}{n_{i 11}}, \forall j, j^{\prime}=2,3, \ldots r, j \neq j^{\prime}
$$

We should mention that from standard normal theory it is known that the multivariate test for $\boldsymbol{\beta}=\mathbf{0}$, based on $\beta^{\prime} \operatorname{cov}(\boldsymbol{\beta})^{-1} \boldsymbol{\beta}$, could yield significant results even if all the $r-1$ univariate Wald tests are non-significant. Thus, the multivariate test should be performed initially and only if a significant result is found we can proceed by collapsing the haplotypes and perform a standard univariate meta-analysis.

The model can be fitted in any statistical package capable of fitting random-effects weighted regression models with an arbitrary covariance matrix, such as SAS (using PROC MIXED or PROC NLMIXED), R (using lme) or Stata (using mvmeta). In this work, we used mvmeta which performs inferences based on either Maximum Likelihood (ML) or Restricted Maximum Likelihood (REML), by direct maximization of the approximate likelihood using a Newton-Raphson algorithm [63]. Alternatively, mvmeta can also implement the multivariate version of the DerSimonian and Laird's method of moments [64]. The last option, being non-iterative, is very attractive in case of large number of haplotypes and/or large number of studies. A major disadvantage of the methods proposed in this section is the assumptions of normality that are employed and the need for correction when there are rare haplotypes (i.e. adding a pseudocount of 0.5 to the haplotypes with zero counts). These limitations are surpassed by using the methods discussed in the next section.

\section{Meta-analysis using binary data}

In this section, methods that use directly the binary nature of the data, within a generalized linear mixed model (GLMM) are presented. These methods are usually termed IPD methods [33-37] although in many real-life applications, individual data may not be literally available. Instead, extending the models described for a single study, only summary counts of individuals carrying the respective haplotypes will normally be used.

\section{Logistic regression}

Using the prospective likelihood we can extend the logistic regression model of Eq. (1) in order to incorporate study specific effects and perform a stratified analysis (fixed effects meta-analysis). To do so, we need to introduce $k-1$ dummy variables $d_{i}$ (taking values equal to zero or one) with coefficients $\beta_{0 i}$ that are indicators of the study-specific fixed-effects. Thus, the model is a straightforward extension to the model described previously for meta-analysis of genetic association studies for single nucleotide polymorphisms [16] and is formulated as:

$$
\begin{aligned}
\operatorname{logit}\left(\pi_{i j}\right) & =\operatorname{logit}\left[P\left(y_{i j}=1 \mid j\right)\right] \\
& =\beta_{0}+\beta_{0 i} d_{i}+\sum_{j=2}^{r} \beta_{j} z_{j}
\end{aligned}
$$


Here, the $\beta_{j}$ obtained by fitting the model are the overall estimates of the logORs (i.e. for comparing $h_{j}$ vs. $h_{1}$ ). An overall test for the association of haplotypes with disease can be performed if we denote by $\boldsymbol{\beta}$ the vector of the estimated coefficients and by $\operatorname{cov}(\boldsymbol{\beta})$ its estimated variance-covariance matrix. Then, the test statistic $U=\boldsymbol{\beta}^{\prime} \operatorname{cov}(\boldsymbol{\beta})^{-1} \boldsymbol{\beta}$ will have asymptotically a $\chi^{2}$ distribution $\left(U \sim \chi_{r-1}^{2}\right)$ [65]. The particular model has been used in several meta-analyses of haplotype association studies [66-69] (see in the results section, the empirical evaluation of the literature). This fixed effects model assumes homogeneity of ORs between studies. This assumption can be tested by adding the interaction between the study effect and the haplotypes into the model::

$$
\begin{aligned}
\operatorname{logit}\left(\pi_{i j}\right)= & \operatorname{logit}\left[P\left(y_{i j}=1 \mid j\right)\right] \\
= & \beta_{0}+\beta_{0 i} d_{i}+\sum_{j=2}^{r} \beta_{j} z_{j} \\
& +\sum_{j=2}^{r} \sum_{i=2}^{k} \gamma_{i j} d_{i} z_{j}
\end{aligned}
$$

This is the analogue to the Cochran's test for heterogeneity in the univariate meta-analysis. The hypothesis can be tested by performing a multivariate Wald test, where the null hypothesis is:

$$
H_{0}: \gamma=0\left(\gamma_{i j}=0, \forall i=2,3, \ldots, k ; j=2,3, \ldots, r\right)
$$

The test statistic can be constructed analogously to the one used for $\boldsymbol{\beta}$. If we denote by $\boldsymbol{\gamma}$ the vector of the estimated coefficients, by $\mathbf{V}$ the estimated variance-covariance matrix and by $\mathbf{R} \boldsymbol{\gamma}=\mathbf{r}$ the vector of the $(r-1)(k-1)$ linear hypotheses, then the statistic:

$$
W=(\mathbf{R} \gamma-\mathbf{r})^{\prime}\left(\mathbf{R V R}^{\prime}\right)^{-1}(\mathbf{R} \boldsymbol{\gamma}-\mathbf{r})=\boldsymbol{\gamma}^{\prime} \operatorname{cov}(\boldsymbol{\gamma})^{-1} \gamma
$$

will have asymptotically a $\chi^{2}$ distribution [65]

$$
W \sim \chi_{(r-1)(k-1)}^{2}
$$

Moreover, the value of $W$ could be used in order to calculate a modified version of the overall inconsistency index $I^{2}$ [70]:

$$
I^{2}=\max \left\{0, \frac{W-(r-1)(k-1)}{W}\right\}
$$

This measure is quite useful, since it enables us to summarize the overall heterogeneity, instead of having to look at multiple indices of heterogeneity arising from multiple haplotype contrasts.

In order to account for an additive component of heterogeneity and perform a random-effects logistic regression allowing the haplotype effects to vary between studies, the most suitable way is to introduce a set of study-specific random coefficients, representing the deviation of study's true effect from the overall mean effect for each haplotype. Thus, the model becomes:

$$
\begin{aligned}
\operatorname{logit}\left(\pi_{i j}\right) & =\operatorname{logit}\left[P\left(y_{i j}=1 \mid j\right)\right] \\
& =\beta_{0}+\beta_{0 i} d_{i}+\sum_{j=2}^{r}\left(\beta_{j}+\beta_{j i}\right) z_{j}
\end{aligned}
$$

In this model, the random terms $\boldsymbol{\beta}_{i}$ are distributed as:

$$
\boldsymbol{\beta}_{i} \sim \operatorname{MVN}(0, \Sigma)
$$

where

$$
\begin{aligned}
\boldsymbol{\beta}_{i} & \left(\begin{array}{c}
\beta_{2 i} \\
\beta_{3 i} \\
\ldots \\
\beta_{r i}
\end{array}\right) \\
\boldsymbol{\Sigma} & =\left(\begin{array}{cccc}
\tau_{2}^{2} & \rho_{B 23} \tau_{2} \tau_{3} & \ldots & \rho_{B r 2} \tau_{2} \tau_{r} \\
\rho_{B 23} \tau_{2} \tau_{3} & \tau_{3}^{2} & \ldots & \rho_{B r 3} \tau_{3} \tau_{r} \\
\ldots & \ldots & \ldots & \ldots \\
\rho_{B r 2} \tau_{2} \tau_{r} & \rho_{B r 3} \tau_{3} \tau_{r} & \ldots & \tau_{r}^{2}
\end{array}\right)
\end{aligned}
$$

The between studies variances and covariances have the same interpretation as the ones obtained by the summary-data methods of Eq. (13) and (15).

\section{Multinomial logistic regression}

Alternatively, the model may be parameterized assuming a multinomial sampling scheme utilizing the retrospective likelihood. In this case, an extension of the model of Eq. (2), which incorporates fixed-study effects, would be:

$$
p_{i j}=P\left(j \mid \gamma_{i j}\right)=\frac{\exp \left(\alpha_{j}+\alpha_{i j} d_{i}+\beta_{j} y_{i j}\right)}{\sum_{j=1}^{r} \exp \left(\alpha_{j}+\alpha_{i j} d_{i}+\beta_{j} y_{i j}\right)}
$$

The linear predictor in the above model becomes:

$$
U_{i j}=\log \left(\frac{p_{i j}}{p_{i 1}}\right)=\alpha_{j}+\alpha_{i j} d_{i}+\beta_{j} y_{i j}, j=1,2, \ldots, r
$$


Similar to the model based on prospective likelihood, the variables $d_{i}$ are indicators of the study-specific fixedeffects. An overall test for the association of haplotypes with disease $(\boldsymbol{\beta}=\mathbf{0})$ can be performed similarly to the logistic regression model $(U)$. Introducing the study by disease interaction terms can form a test for homogeneity of ORs across the $\mathrm{k}$ studies:

$$
\begin{gathered}
U_{i j}=\log \left(\frac{p_{i j}}{p_{i 1}}\right)=\alpha_{j}+\alpha_{i j} d_{i}+\beta_{j} y_{i j}+\sum_{i=2}^{k} \sum_{j=2}^{r} \gamma_{i j} d_{i} y_{i j} \\
j=1,2, \ldots, r
\end{gathered}
$$

The statistics for heterogeneity $(W)$ as well as the $I^{2}$ index derived from it are identical to the one presented in Eq. (19) - (21).

A random-effects extension to the model can be formulated if in the above model, we introduce a haplotype-specific random coefficient $\beta_{i j}$ (for haplotypes $j=$ $2,3, \ldots, r)$, in which case the linear predictor becomes [71]:

$$
\begin{array}{r}
U_{i j}=\log \left(\frac{p_{i j}}{p_{i 1}}\right)=\alpha_{j}+\alpha_{i j} d_{i}+\beta_{j} y_{i j}+\beta_{i j} y_{i j} \\
j=2,3, \ldots, r
\end{array}
$$

and the model is completely specified as a random effects multivariate meta-analysis, with random terms $\boldsymbol{\beta}_{i}$ distributed similarly as $\boldsymbol{\beta}_{i} \sim M V N(\mathbf{0}, \boldsymbol{\Sigma})$. The interpretation of the variances and covariances of the random terms is identical to the ones presented in Eq. (13). A version of this model has been used previously for meta-analysis of genetic association studies involving single nucleotide polymorphisms [12], but according to the author's knowledge it has never been used for meta-analysis of haplotypes.

\section{Poisson regression}

Lastly, we can extend the log-linear model of Eq. (4) in order to perform a fixed effects meta-analysis allowing for the study-specific effects. The major difference compared to the previous approaches lies in the structure of the log-linear model and the interpretation of the main effects and interactions. Having in mind that we want to model a $2 \times r \times k$ contingency table, the appropriate choice would be to include in the model of Eq. (4) the study specific main effects as well as the two-way interactions (study $\mathrm{x}$ disease and study $\mathrm{x}$ haplotype). Thus, we would have a model containing all the main effects as well as all the two-way interactions, a model known as the "no three-factor interaction model" [45]:

$$
\begin{aligned}
\log \left(n_{i j}\right) & =\mu_{0}+\mu_{i} d_{i}+\beta_{0} y_{i j} \\
& +\sum_{j=2}^{r} a_{j} z_{j}+\sum_{j=2}^{r} \beta_{j} z_{j} y_{i j} \\
& +\sum_{j=2}^{r} \sum_{i=2}^{k} a_{i j} z_{j} d_{i}+\sum_{i=2}^{k} \beta_{0 i} y_{i j} d_{i}
\end{aligned}
$$

In this model, the coefficients $\alpha_{j}, \alpha_{i j}, \beta_{0}, \beta_{0 j}$ and $\beta_{j}$ correspond to the ones obtained by fitting the models in Eq. (17) and Eq. (15). The overall test for the association of the haplotypes with the disease $(\boldsymbol{\beta}=\mathbf{0})$, is known in the context of log-linear models as the test of "partial association" [72,73]. The model in Eq. (29), assumes homogeneity of ORs across studies. Thus, in order to test this assumption we need to include additional terms for the three-way interaction (study $\mathrm{x}$ disease $\mathrm{x}$ haplotype). This is accomplished by fitting the saturated model:

$$
\begin{aligned}
\log \left(n_{i j}\right) & =\mu_{0}+\mu_{i} d_{i}+\beta_{0} y_{i j} \\
& +\sum_{j=2}^{r} a_{j} z_{j}+\sum_{j=2}^{r} \beta_{j} z_{j} y_{i j} \\
& +\sum_{j=2}^{r} \sum_{i=2}^{k} a_{i j} z_{j} d_{i}+\sum_{i=2}^{k} \beta_{0 i} y_{i j} d_{i} \\
& +\sum_{j=2}^{r} \sum_{i=2}^{k} \gamma_{i j} z_{j} d_{i} y_{i j}
\end{aligned}
$$

The test with the null hypothesis $H_{0}: \boldsymbol{\gamma}=\mathbf{0}\left(\gamma_{i j}=0, i=\right.$ $2,3, \ldots, k, j=2,3, \ldots, r)$ is identical to the ones obtained by fitting the models in Eq. (18) and (27). The three-way interaction model and its interpretation in terms of testing the homogeneity of ORs has been discussed in detail in the past [45,74-76]. Log-linear models have been employed in several meta-analyses of haplotype association $[77,78]$ (see in the results section). However, even though not described in detail, it is apparent from the results reported, that in these analyses the log-linear model was not applied in an appropriate manner. Although the authors stated that they performed stratification by study, they probably included only the main effect of the study and not the interaction terms with both haplotypes and disease. As we will see in the results section, when the correct model is applied, the originally drawn conclusions are compromised.

In analogy to models in Eq. (22) and (28), a random coefficient for the disease by haplotype interaction can 
be applied in order to perform a random-effects metaanalysis:

$$
\begin{aligned}
\log \left(n_{i j}\right) & =\mu_{0}+\mu_{i} d_{i}+\beta_{0} y_{i j} \\
& +\sum_{j=2}^{r} a_{j} z_{j}+\sum_{j=2}^{r}\left(\beta_{j}+\beta_{j i}\right) z_{j} y_{i j} \\
& +\sum_{j=2}^{r} \sum_{i=2}^{k} a_{i j} z_{j} d_{i}+\sum_{i=2}^{k} \beta_{0 i} y_{i j} d_{i}
\end{aligned}
$$

with random terms $\boldsymbol{\beta}_{i}$ distributed similarly as $\boldsymbol{\beta}_{i} \sim M V N$ $(\mathbf{0}, \mathbf{\Sigma})$. Similarly to the multinomial logistic regression model, the interpretation of the variances and covariances of the random terms is identical to the ones presented in Eq. (12).

\section{Continuous traits}

The methods discussed so far assume we are dealing with a binary trait, usually in a case-control setting. However, continuous traits are not uncommon in genetic association studies and these should be easily accommodated using a linear model (linear regression). For instance, denoting by $y_{i j}$ the continuous trait for a person carrying the $j^{\text {th }}$ haplotype in the $i^{\text {th }}$ study, the model would be:

$$
y_{i j}=\beta_{0}+\beta_{0 i} d_{i}+\sum_{j=2}^{r} \beta_{j} z_{j}
$$

The homogeneity of haplotype effects across studies can be subsequently checked using a model with a haplotype $\mathrm{x}$ study interaction term:

$$
\gamma_{i j}=\beta_{0}+\beta_{0 i} d_{i}+\sum_{j=2}^{r} \beta_{j} z_{j}+\sum_{j=2}^{r} \sum_{i=2}^{k} \gamma_{i j} d_{i} z_{j}
$$

Finally, a random effects model could be formulated using a liner mixed model:

$$
y_{i j}=\beta_{0}+\beta_{0 i} d_{i}+\sum_{j=2}^{r}\left(\beta_{j}+\beta_{j i}\right) z_{j}
$$

with random terms $\boldsymbol{\beta}_{i}$ distributed similarly as $\boldsymbol{\beta}_{i} \sim M V N(\mathbf{0}, \boldsymbol{\Sigma})$. Similarly to the previously described models, the interpretation of the variances and covariances of the random terms is identical to the ones presented in Eq. (12). In case where individual data are not available, the above models could be easily fitted using summary data (mean values and standard deviations) per haplotype.

\section{Implementation}

The models presented in this section can be easily fitted in Stata using gllamm, or in SAS using PROC NLMIXED. These models are expected to perform better compared to the models presented in the previous section, in case the normality assumption for logORs does not hold. Furthermore, a major advantage of these models is that they can directly be used for pooled metaanalyses performed under large collaborative projects. This is why these models are usually termed Individual Patients Data (IPD) methods [36]. However, a disadvantage is that these methods are computational intensive, especially when the number of haplotypes is large.

A sometimes useful simplification can be made in Eq. (15) if we assume that the between-studies variances are equal [34]. In such case by letting $\tau=\tau_{2}=\tau_{3}=\ldots=\tau_{r}, \boldsymbol{\Sigma}$ reduces to:

$$
\boldsymbol{\Sigma}=\left(\begin{array}{cccc}
\tau^{2} & \rho \tau^{2} & \ldots & \rho \tau^{2} \\
\rho \tau^{2} & \tau^{2} & \ldots & \rho \tau^{2} \\
\ldots & \ldots & \ldots & \ldots \\
\rho \tau^{2} & \rho \tau^{2} & \ldots & \tau^{2}
\end{array}\right)
$$

Another approximation would be to impose a single between studies correlation, but allow for different between-studies variances [79]:

$$
\Sigma=\left(\begin{array}{cccc}
\tau_{2}^{2} & \rho \tau_{2} \tau_{3} & \ldots & \rho \tau_{2} \tau_{r} \\
\rho \tau_{2} \tau_{3} & \tau_{3}^{2} & \ldots & \rho \tau_{3} \tau_{r} \\
\ldots & \ldots & \ldots & \ldots \\
\rho \tau_{2} \tau_{r} & \rho \tau_{3} \tau_{r} & \ldots & \tau_{r}^{2}
\end{array}\right)
$$

In this work however, we chose to use a different approximation that can be obtained if the number of random effects is reduced by decomposing the random terms using factor loadings such as: $\tau_{2}{ }^{2}=\lambda_{2}{ }^{2} \tau^{2}, \tau_{3}{ }^{2}=$ $\lambda_{3}{ }^{2} \tau^{2}, \ldots, \tau_{r}{ }^{2}=\lambda_{r}{ }^{2} \tau^{2}$, and letting $\lambda_{2}=1$ for identification. Thus, the covariance matrix becomes now:

$$
\Sigma=\left(\begin{array}{cccc}
\tau^{2} & \lambda_{3} \tau^{2} & \ldots & \lambda_{r} \tau^{2} \\
\lambda_{3} \tau^{2} & \lambda_{3}^{2} \tau^{2} & \ldots & \lambda_{3} \lambda_{r} \tau^{2} \\
\ldots & \ldots & \ldots & \ldots \\
\lambda_{r} \tau^{2} & \lambda_{3} \lambda_{r} \tau^{2} & \ldots & \lambda_{r}^{2} \tau^{2}
\end{array}\right)
$$

The particular approximation is conceptually similar to the one used previously for the so-called "genetic model-free approach" for meta-analysis of genetic association studies $[14,80]$, even though the motivation was different. The model imposes a single between studies variance $\tau^{2}$ thus, it is much faster since the factor 
loadings $\lambda_{j}$ with $j=3,4, \ldots, r$ are treated as fixed-effects parameters. By observing also the off-diagonal elements of the covariance matrix in Eq. (37), we can see that the model restricts the between-studies correlations $\left(\rho_{B i j^{\prime}}\right)$ to be equal to \pm 1 (depending on the sign of $\lambda_{j} \lambda_{j^{\prime}}$ ). Nevertheless, the between-studies correlations are usually poorly estimated especially when the number of studies is small $(<20)$ and in such cases they are usually estimated to be equal to $\pm 1[81,82]$. Thus, the particular approach seems to be a good compromise between speed and precision and we expect to perform well. Using this approach, the computational complexity as well as the execution time is reduced drastically but the obtained estimates agree up to the fourth decimal place in most of the experiments conducted.

A final comment has to be made concerning the identifiability of the models presented in the previous sections, especially when it comes to the log-linear models which are the ones that contain the largest number of parameters. Concerning the fixed effects methods, the number of parameters of the saturated model of Eq. (30) is equal to $2 r k$, a number that is equal to the number of observations [45]. For the model of Eq. (29), the number of freely estimated parameters is equal to $r k+r+k-1$, which is obviously smaller than $2 r k$ (since $r>1$ and $k>$ 1). The random effects model of Eq. (31) has a total number of parameters equal to $r k+r+k-1+r(r-1) / 2$ since we need to estimate additionally $r(r-1) / 2$ elements of the covariance matrix (the variances and the covariances of the random effects). Thus, in order for the model to be identifiable we need to ensure that $r k+r+k-1+r(r-1) / 2$ $\leq 2 r k$ which is accomplished if $k ; \geq 1+r / 2$. Intuitively, we need a relatively larger number of studies compared to the number of haplotypes. If on the other hand, we fit the model of Eq. (31) using Eq. (35) for restricting the covariances, we only need $r k+r+k$ parameters and when we use Eq. (36) or Eq. (37), we need to estimate $r k$ $+2 r+k-1$ parameters, numbers which both are smaller than $2 r k$. Nevertheless, for practical applications, we will normally use the logistic regression model of Eq. (22) coupled with parameterization of Eq. (37), and thus identifiability issues will never arise in practice.

In Additional file 1, Stata programs for fitting the models developed in this section are presented. The models were fitted using the gllamm module for Stata $[83,84]$. gl lamm uses numerical integration by adaptive quadrature in order to integrate out the latent variables and obtain the marginal log-likelihood. Afterwards, the log-likelihood is maximized by Newton-Raphson using numerical first and second derivatives.

\section{Results}

We initially performed a literature search for identifying studies that report meta-analyses of haplotype associations. The initial search in PUBMED using the term "haplotype" combined with "meta-analysis" or "collaborative analysis" or "pooled analysis" yielded 282 studies. Of these, 35 studies could have been identified using solely the terms "collaborative analysis" or "pooled analysis" and "haplotype". After careful screening, 207 studies were excluded as irrelevant ones (they were not meta-analyses of haplotypes), 36 studies were excluded for various reasons (family based-studies, meta-analyses of SNPs with the term "haplotype" appearing in the abstract or haplotype analyses in which the term "metaanalysis" appeared in the abstract etc). Finally, we came up with 39 published papers containing data for 43 associations. Some studies reported different sets of haplotypes from the same gene (Auburn et al, 2008; Zintzaras et al, 2009), haplotypes from different genes (Thakkinstian et al, 2008), or distinct outcomes measured on different subsets of patients (Kavvoura et al, 2007) and thus, they were included twice, whereas from studies that reported different outcomes measured on the same set of individuals we kept only one. There were also some pairs of studies that evaluated the same association and from these we kept only the largest one. 10 out of the 39 published papers could have been identified using solely the terms "collaborative analysis" or "pooled analysis" coupled with the term "haplotype". The 43 studies and their characteristics are presented in Table 2.

The average number of polymorphisms included in the haplotypes was $3.19(\mathrm{SD}=1.37$, median $=3$, range from 2 to 7), whereas the sample size was 5,017.81 (SD $=4,703 \cdot 24$, median $=3,004$, range from 348 to 23,309). The average number of included studies was 5.14 (SD = 3.06 , median $=4$, range from 2 to 13 ). Twenty seven studies $(62.79 \%)$ were conducted in a collaborative setting, whereas sixteen $(37.21 \%)$ were performed using data derived from the literature. Twenty seven of the meta-analyses (62.79\%) reported significant results and the majority ( 22 studies, $51.16 \%$ ) were analysed under the " 1 vs. others" approach using standard summary based meta-analysis techniques (with fixed or random effects), 11 studies $(25.58 \%)$ were analysed by pooling the data inappropriately, 6 studies (13.95\%) did not report the method or did not perform pooling at all and 4 analyses $(9.30 \%)$ were performed using a fixed effects logistic regression model. Only 13 studies (30.23\%) reported the complete data that suffice for the analysis to be replicated (Table 2 and 3).

There was only some weak evidence where collaborative meta-analyses contained larger number of studies compared to literature-based ones (5.67 vs. 4.25), larger sample size $(5,651$ vs. 3,948$)$ and produced significant results more frequently (66.67\% vs. $56.25 \%)$. However, these differences did noreach statistical significance 
Table 2 List of the $\mathbf{4 3}$ meta-analyses that were used in the empirical evaluation

\begin{tabular}{|c|c|c|c|c|c|c|c|c|c|c|}
\hline ID & Reference & $\begin{array}{l}\text { Gene/ } \\
\text { Locus }\end{array}$ & $\begin{array}{l}\text { Disease/ } \\
\text { Outcome }\end{array}$ & $\begin{array}{l}\text { SNPs in } \\
\text { haplotype }\end{array}$ & $\begin{array}{l}\text { Number of } \\
\text { studies }\end{array}$ & $\begin{array}{l}\text { Sample } \\
\text { Size }\end{array}$ & $\begin{array}{l}\text { Method of } \\
\text { analysis }\end{array}$ & $\begin{array}{c}\text { Data } \\
\text { availability }\end{array}$ & $\begin{array}{c}\text { Collaborative } \\
\text { analysis }\end{array}$ & $\begin{array}{l}\text { Significant } \\
\text { results }\end{array}$ \\
\hline 1 & [109] & DRD3 & Schizophrenia & 4 & 5 & 7551 & 1 vs. others & No & No & No \\
\hline 2 & [98] & ITGAV & $\begin{array}{l}\text { Rheumatoid } \\
\text { Arthritis }\end{array}$ & 3 & 3 & 6851 & N/A & Yes & Yes & Yes \\
\hline 3 & [110] & $\begin{array}{l}\text { IL1A/IL1B/ } \\
\text { IL1RN }\end{array}$ & Osteoarthritis & 7 & 4 & 2908 & 1 vs. others & No & Yes & Yes \\
\hline 4 & [1111] & FRZB & Osteoarthritis & 2 & 10 & 12380 & 1 vs. others & No & Yes & No \\
\hline 5 & [99] & CX3CR1 & CAD & 2 & 6 & 2912 & 1 vs. others & Yes & No & Yes \\
\hline 6 & [112] & ALOX5AP & Stroke & 4 & 5 & 5765 & 1 vs. others & No & No & No \\
\hline 7 & [112] & ALOX5AP & Stroke & 4 & 3 & 3004 & 1 vs. others & No & No & No \\
\hline 8 & [113] & GNAS & Malaria & 3 & 7 & 8154 & 1 vs. others & No & Yes & Yes \\
\hline 9 & [113] & GNAS & Malaria & 7 & 6 & 7632 & 1 vs. others & No & Yes & Yes \\
\hline 10 & [114] & PDLIM5 & $\begin{array}{l}\text { Bipolar } \\
\text { Disorder }\end{array}$ & 2 & 3 & 1208 & 1 vs. others & No & No & No \\
\hline 11 & [115] & PDE4D & Stroke & 2 & 4 & 4961 & 1 vs. others & No & No & Yes \\
\hline 12 & [116] & TGFB1 & $\begin{array}{c}\text { Renal } \\
\text { Transplantation }\end{array}$ & 2 & 4 & 438 & pooled & No & No & Yes \\
\hline 13 & [116] & IL10 & $\begin{array}{c}\text { Renal } \\
\text { Transplantation }\end{array}$ & 3 & 4 & 348 & pooled & No & No & No \\
\hline 14 & [117] & $9 p 21.3$ & CAD & 4 & 5 & 7838 & 1 vs. others & No & Yes & Yes \\
\hline 15 & [118] & HLA & SLE & 2 & 3 & 527 & 1 vs. others & No & No & Yes \\
\hline 16 & {$[94]$} & CTLA4 & Graves Disease & 2 & 10 & 2564 & 1 vs. others & Yes & Yes & Yes \\
\hline 17 & [94] & CTLA4 & $\begin{array}{l}\text { Hashimoto } \\
\text { Thyroiditis }\end{array}$ & 2 & 5 & 1210 & 1 vs. others & Yes & Yes & Yes \\
\hline 18 & [119] & ENPP1 & T2DM & 3 & 3 & 8676 & 1 vs. others & No & No & No \\
\hline 19 & {$[77]$} & MTHFR & ALL & 2 & 4 & 894 & $\begin{array}{l}\text { Log-linear } \\
\text { model }\end{array}$ & No & No & Yes \\
\hline 20 & [97] & CAPN10 & T2DM & 3 & 11 & 5862 & 1 vs. others & Yes & Yes & Yes \\
\hline 21 & [93] & ADAM33 & Asthma & 5 & 3 & 1899 & pooled & Yes & No & No \\
\hline 22 & {$[120]$} & NRG1 & Schizophrenia & 6 & 11 & 8722 & 1 vs. others & No & No & Yes \\
\hline 23 & [121] & RGS4 & Schizophrenia & 4 & 8 & 7243 & 1 vs. others & No & Yes & No \\
\hline 24 & {$[122]$} & ADRB2 & Asthma & 2 & 3 & 2060 & N/A & No & No & Yes \\
\hline 25 & [123] & ESR1 & Fractures & 3 & 8 & 14622 & 1 vs. others & No & Yes & Yes \\
\hline 26 & [78] & VDR & Osteoporosis & 3 & 4 & 2335 & $\begin{array}{l}\text { Log-linear } \\
\text { model }\end{array}$ & Yes & No & Yes \\
\hline 27 & [95] & ACE & $\begin{array}{l}\text { Alzheimer's } \\
\text { Disease }\end{array}$ & 3 & 4 & 1619 & pooled & Yes & Yes & Yes \\
\hline 28 & [124] & |GF-| & |GF-I levels & 3 & 3 & 1929 & 1 vs. others & No & Yes & Yes \\
\hline 29 & {$[125]$} & TF & Stroke & 2 & 2 & 818 & N/A & No & Yes & No \\
\hline 30 & [92] & FcgammaR & Celliac Disease & 2 & 2 & 1057 & N/A & Yes & Yes & No \\
\hline 31 & [69] & VDR & Fractures & 3 & 9 & 23309 & $\begin{array}{l}\text { Logistic } \\
\text { regression }\end{array}$ & No & Yes & No \\
\hline 32 & [96] & G72/G30 & Schizophrenia & 2 & 2 & 1541 & N/A & Yes & Yes & Yes \\
\hline 33 & [68] & VEGF & ALS & 3 & 4 & 1912 & $\begin{array}{l}\text { Logistic } \\
\text { regression }\end{array}$ & Yes & Yes & Yes \\
\hline 34 & {$[126]$} & BANK1 & $\begin{array}{l}\text { Rheumatoid } \\
\text { Arthritis }\end{array}$ & 3 & 4 & 4445 & 1 vs. others & No & Yes & Yes \\
\hline 35 & {$[67]$} & CYP19A1 & $\begin{array}{l}\text { Endometrial } \\
\text { Cancer }\end{array}$ & 2 & 10 & 13283 & $\begin{array}{l}\text { Logistic } \\
\text { regression }\end{array}$ & No & Yes & Yes \\
\hline 36 & [127] & CRP & T2DM & 3 & 3 & 11876 & N/A & No & No & Yes \\
\hline 37 & {$[66]$} & $8 q 24$ & $\begin{array}{l}\text { Colorectal } \\
\text { Adenoma }\end{array}$ & 4 & 3 & 5385 & $\begin{array}{l}\text { Logistic } \\
\text { regression }\end{array}$ & No & Yes & Yes \\
\hline 38 & [128] & CYP1A1 & Lung Cancer & 2 & 13 & 2151 & Pooled & No & Yes & Yes \\
\hline
\end{tabular}


Table 2 List of the $\mathbf{4 3}$ meta-analyses that were used in the empirical evaluation (Continued)

\begin{tabular}{ccccccccccc}
\hline 39 & {$[91]$} & TNFA & Prostate Cancer & 5 & 2 & 4881 & Pooled & Yes & Yes & No \\
40 & {$[90]$} & PTGS2 & Prostate Cancer & 4 & 2 & 4881 & Pooled & Yes & Yes & No \\
41 & {$[129]$} & AR & $\begin{array}{c}\text { Endometrial } \\
\text { Cancer }\end{array}$ & 5 & 2 & 1424 & Pooled & No & Yes & No \\
42 & {$[130]$} & MGMT & $\begin{array}{c}\text { Head and Neck } \\
\text { Cancer }\end{array}$ & 2 & 3 & 1347 & Pooled & No & Yes & Yes \\
43 & {$[131]$} & SNCA & $\begin{array}{c}\text { Parkinson } \\
\text { Disease }\end{array}$ & 2 & 11 & 5344 & 1 vs. other & No & Yes \\
\hline
\end{tabular}

We list the reference, the gene name, the disease, the number of SNPs included in the haplotypes, the number of studies, the total sample size, the method of analysis (N/A: not available), the availability of data, whether the data was collected in a collaborative setting and whether the study reported significant results.

(p-values equal to $0.144,0.256$ and 0.506 respectively). The average number of included polymorphisms was also comparable (3.26 vs. 3.06, p-value $=0.654)$. The thirteen meta-analyses that reported complete data, did not differ significantly from the remaining ones in terms of the included studies ( 4.46 vs. 5.43 , p-value $=0.345$ ), the number of SNPs in the haplotypes (3.08 vs. 3.23, pvalue $=0.735)$ and the proportion of significant findings $(69.23 \%$ vs. $60 \%$, p-value $=0.576)$. The proportion of collaborative analyses was higher, even though this difference did not reach statistical significance $(76.92 \%$ vs. $56.57 \%$, p-value $=0.216$ ). There was however, moderate evidence that the total sample size included in the meta-analyses that reported complete data was smaller compared to the meta-analyses that did not $(3,040.31$ vs. $5,874.73$, p-value $=0.069$ ). We also compared the particular database against a database of 55 representative meta-analyses of genetic association studies of SNPs that was used previously in several empirical evaluations [85-89]. The mean sample size was approximately equal $(5,017$ vs. 4,829 , $\mathrm{p}$-value $=0.844)$, but the number of included studies was nearly halved in the meta-analyses of haplotypes (5.14 vs. 10.53, p-value $<10^{-4}$ ), whereas the proportion of meta-analyses with significant results was twice as large $(62.8 \%$ vs. $27.27 \%$, p-value $=0.0003)$.

The thirteen studies that reported the data necessary for the analysis to be replicated were subsequently used in order to apply the methods proposed in this work. We used all the methods described in the methods section except for the simpler approach of comparing 1 vs. the others haplotypes, i.e. Eq.(5). The results are reported in Table 3, where we list the p-values for the tests for the overall association $(\boldsymbol{\beta}=\mathbf{0})$. For the fixed effects IPD methods we additionally report the p-value of the overall test for the heterogeneity $(\gamma=\mathbf{0})$. Concerning the results obtained using the IPD methods, we report only the ones obtained from the logistic regression method of Eq. (22) using the parameterization of Eq. (37) which is easier to be fitted, even though the multinomial logistic regression and the Poisson regression method would yield similar results. As expected, when the heterogeneity is low (in 8 out of the 13 studies), the random effects methods coincide with their fixed effects counterparts. In general, the methods that use summary data yield slightly different estimates for the ORs compared to the methods that use IPD, when there were rare haplotypes (i.e. small counts) or when the total number of subjects was low (data not shown). In 2 out of the 13 studies the estimates for the multivariate Wald tests for the overall association $(\boldsymbol{\beta}=\mathbf{0})$ produce marginally different results compared to the univariate ones.

The subsequent re-analysis and the contrasting with the initial reports yielded some important findings. Concerning the four studies that initially reported no significant association [90-93], the methods presented in this work largely support the initial conclusions. Three of the nine studies (33.33\%) that reported statistically significant results $[94,95]$ yielded results that are in complete agreement with the initial reports (the metaanalysis of Kavvoura and co-workers reported results for two outcomes and it was counted twice). The most important finding, however, was the observation that 4 out of the 9 studies (44.44\%) [78,96-98], yielded results that contradict the initial reports. Two additional studies $[68,99]$ produced marginally significant results as judged by the disagreement between the multivariate and univariate Wald tests (Table 3 ).

The reasons for these discrepancies deserve further investigation. For instance, in the collaborative metaanalysis for the association of CAPN10 haplotypes with Type 2 Diabetes mellitus [97], the authors report a marginally significant OR of $1.09(1.00,1.18)$ for the "1-2-1" haplotype and similar results for two haplogenotypes that include this haplotype. Similar results were previously reported in a literature-based meta-analysis [100]. However, these estimates have been derived using the "1 vs. others" approach, which although more powerful, it is known to suffer from increase type I error rate; thus it seems that these estimates are the result of a multiple testing procedure. For the metaanalysis concerning the association of ITGAV haplotypes with Rheumatoid Arthritis [98], as well as the association of G30/G72 haplotypes with schizophrenia 
Table 3 The results obtained using the methods described in this work on the 13 studies that reported complete data that suffice for the analysis to be replicated

\begin{tabular}{|c|c|c|c|c|c|c|c|c|c|c|}
\hline \multirow{2}{*}{$\begin{array}{c}\mathrm{ID} / \\
\text { [reference] }\end{array}$} & \multirow{2}{*}{$\begin{array}{l}\text { Gene/ } \\
\text { Locus }\end{array}$} & \multirow{2}{*}{$\begin{array}{l}\text { Disease/ } \\
\text { Outcome }\end{array}$} & \multirow{2}{*}{$\begin{array}{l}\text { SNPs in } \\
\text { haplotype }\end{array}$} & \multirow{2}{*}{$\begin{array}{l}\text { Number of } \\
\text { studies }\end{array}$} & \multirow{2}{*}{$\begin{array}{l}\text { Significant } \\
\text { results }\end{array}$} & \multicolumn{3}{|c|}{ Fixed effects } & \multicolumn{2}{|c|}{ Random effects } \\
\hline & & & & & & $\begin{array}{c}\beta=0 \\
\text { (summary } \\
\text { data) }\end{array}$ & $\begin{array}{l}\beta=0 \\
\text { (IPD) }\end{array}$ & $\begin{array}{l}\gamma=0 \\
\text { (IPD) }\end{array}$ & $\begin{array}{c}\beta=0 \\
\text { (summary } \\
\text { data) }\end{array}$ & $\begin{array}{l}\beta=0 \\
\text { (IPD) }\end{array}$ \\
\hline $2 /[98]$ & ITGAV & $\begin{array}{l}\text { Rheumatoid } \\
\text { Arthritis }\end{array}$ & 3 & 3 & $\mathrm{Yes}^{\$ \$}$ & 0.2506 & 0.2489 & 0.1564 & 0.3288 & 0.3851 \\
\hline $5 /[99]$ & CX3CR1 & CAD & 2 & 6 & $\mathrm{Yes}^{\$}$ & $0.0834^{*}$ & $0.0677^{*}$ & 0.6263 & $0.0883^{*}$ & $0.1031^{*}$ \\
\hline $16 /[94]$ & CTLA4 & $\begin{array}{l}\text { Graves } \\
\text { Disease }\end{array}$ & 2 & 10 & Yes & $<0.0001$ & $<0.0001$ & 0.0371 & $<0.0001$ & $<0.0001$ \\
\hline $17 /[94]$ & CTLA4 & $\begin{array}{l}\text { Hashimoto } \\
\text { Thyroiditis }\end{array}$ & 2 & 5 & Yes & 0.0011 & 0.0010 & $<0.0001$ & 0.0044 & 0.0072 \\
\hline 20/[97] & CAPN10 & T2DM & 3 & 11 & $\mathrm{Yes}^{\$ \$}$ & 0.1152 & 0.1036 & 0.6145 & 0.2243 & 0.1655 \\
\hline $21 /[93]$ & ADAM33 & Asthma & 5 & 3 & No & 0.6209 & 0.5508 & 0.4697 & 0.6134 & 0.5503 \\
\hline 26/[78] & VDR & Osteoporosis & 3 & 4 & $Y_{e s} \$ \$$ & 0.1458 & 0.3051 & $<0.0001$ & 0.1480 & 0.5781 \\
\hline $27 /[95]$ & ACE & $\begin{array}{l}\text { Alzheimer's } \\
\text { Disease }\end{array}$ & 3 & 4 & Yes & 0.0193 & 0.0218 & 0.8906 & 0.0193 & 0.0223 \\
\hline 30/[92] & FcgammaR & $\begin{array}{l}\text { Celliac } \\
\text { Disease }\end{array}$ & 2 & 2 & No & 0.7331 & 0.7335 & 0.9502 & 0.7331 & 0.7336 \\
\hline $32 /[96]$ & G72/G30 & Schizophrenia & 2 & 2 & Yes $s^{\$ \$}$ & 0.7790 & 0.7757 & 0.0001 & 0.5750 & 0.6719 \\
\hline $33 /[68]$ & VEGF & ALS & 3 & 4 & Yes $^{\$}$ & $0.0437^{*}$ & 0.0414 & 0.0691 & 0.0716 & $0.0455^{*}$ \\
\hline 39/[91] & TNFA & $\begin{array}{c}\text { Prostate } \\
\text { Cancer }\end{array}$ & 5 & 2 & No & 0.2531 & 0.2515 & 0.6185 & 0.2867 & 0.2511 \\
\hline 40/[90] & PTGS2 & $\begin{array}{c}\text { Prostate } \\
\text { Cancer }\end{array}$ & 4 & 2 & No & 0.3560 & 0.3550 & 0.2087 & 0.6573 & 0.4829 \\
\hline
\end{tabular}

For either fixed or random effects methods, we list the p-values for the tests for the overall association $(\beta=0)$ using the summary data based methods and the IPD methods. The results for the IPD methods were obtained from the logistic regression method even though the multinomial logistic regression and the Poisson regression method yield nearly identical results. For the fixed effects IPD methods we also list the $p$-value of overall test for the heterogeneity $(\gamma=0)$. $\left(^{*}\right)$ : The significance of the multivariate Wald test $(\beta=0)$ contradicts univariate one $\left(\beta_{j}=0\right)$.

$(\$)$ : The initially claimed statistically significant results are contradicted by either the multivariate or univariate Wald tests (random effects).

$\left({ }^{\$ \$}\right)$ : The initially claimed statistically significant results are contradicted by both the multivariate and univariate Wald tests (random effects).

[96], the authors did not explicitly state how the pooling of estimates was performed, but the methods presented in this work suggest clearly that there is not enough evidence supporting the claimed associations. Finally, in the case of the meta-analysis for the association of VDR polymorphisms with osteoporosis, in which the authors claimed to use a log-linear model [78], the initially drawn conclusions are not supported. It seems that the authors did not use a correctly specified model that contains all the main effects as well as all the two-way interactions (i.e. the "no three-factor interaction model"). This probably resulted in performing a meta-analysis essentially without stratifying by study. Given that in the particular dataset the heterogeneity is large, it is of no surprise that the originally drawn conclusions are compromised after the re-analysis, which strongly indicates that there is no evidence to support a significant association. Concerning the two datasets for which we observed disagreement between the multivariate and univariate Wald tests, i.e. the association of CX3CR1 haplotypes with CAD [99] and the association of VEGF haplotypes with ALS [68], there were different reasons for the discrepancies. In the meta-analysis of CX3CR1 haplotypes (which was originally performed using the "1 vs. others" approach) the small discrepancies could be attributed to the marginal statistical significance (pvalues $=0.06-0.09)$ and the existence of a rare haplotype. In the case of the VEGF meta-analysis, the authors initially used a fixed-effects logistic regression model analogous to Eq. (17); however, the moderate heterogeneity produced slight discrepancies in the results of the multivariate Wald test under the random effects model (Table 3).

\section{Discussion}

Although the studies reporting haplotypes comprise a small fraction of genetic association studies, their number is increasingly growing and so there is a need for developing formal methods for combining them in a meta-analysis. In this work, a comprehensive framework for the meta-analysis of haplotype association studies was presented and an empirical evaluation has been performed for the first time in the literature.

The methods proposed in this work are extending previous works in meta-analysis of genetic association studies $[12,16]$ in order to handle the multiple haplotypes. 
These works in turn, are based on the previously described large corpus of methods for multivariate metaanalysis [33,36,37,62,101-103]. We proposed summarydata based methods as well as methods for IPD. Although the former are very easily implemented, the latter provide some very useful insights. By viewing the meta-analysis data as a $2 \times r \times k$ contingency table [45] allowed developing methods based on logistic regression, multinomial logistic regression and Poisson regression. Although logistic regression methods have long being used for meta-analysis of IPD [33,36,37], multinomial logistic regression has only being used for meta-analysis of genetic association studies under the retrospective likelihood $[12,80]$. Most importantly, Poisson regression models have been used in entirely different contexts, such as survival analysis [104] and meta-analysis of follow-up studies with varying duration [105]. Thus, an important advancement of this work is the extension of the commonly used approach for analyzing haplotype data $[43,44]$ in the meta-analysis setting, describing appropriately specified models and presenting them in a unified framework (i.e. the contingency table analysis).

The empirical evaluation of the published literature suggests that studies reporting meta-analysis of haplotypes did not systematically differ from the meta-analyses of genetic association using SNPs in terms of the average sample size, but contain approximately half of the included studies and produce significant results twice more often. The meta-analyses that reported the complete data did not significantly differ from the remaining studies in terms of the included studies, the number of SNPs included in the haplotypes, the proportion of significant findings or the proportion of collaborative analyses. There was however, moderate evidence that the total sample size included in the meta-analyses that reported complete data, was smaller compared to the meta-analyses that did not.

The application of the methods proposed in this work in studies that reported the complete data, made clear that approximately half of the significant findings are attributable to the method of analysis used by the primary authors and suffer from an inflated type I error rate. Indeed, for the four out of the nine studies that reported significant results, these were clearly refuted by the multivariate methodology. Three of these studies used the 1 vs. other approach, which although more powerful, is known to suffer from increased type I error rate [61], whereas the results of the fourth study were based on a misspecified log-linear model. Two additional studies produced marginally insignificant results (i.e. the multivariate Wald test contradicted the univariate one), mainly due to the existence of rare haplotypes or heterogeneity that has not been accounted for in the initial analysis.
All the models presented here assume that the haplotypes are directly observed. However, as we have already discussed, the haplotypes are usually inferred and thus, treating them as known quantities may be problematic [30]. The general framework presented in this work can be easily extended in order to account for this uncertainty, simply by weighting the inferred haplotypes by their probability $[49,50]$. However, this will probably be problematic in many real life applications, except when dealing with a collaborative analysis, since a metaanalyst will rarely have access to individual genotype data in order to use them to estimate the haplotypes and their posterior probabilities. If combined genotypes are available for all studies, the meta-analyst may try to re-construct the haplotypes with a method of his/her choice and perform the analysis using the posterior probabilities as weights. Moreover, if individual genotype data is available (from the literature or in a collaborative setting), the framework can be extended to allow the haplotype risk to follow models of inheritance other than the multiplicative one (i.e. estimating the risk of haplogenotypes), or to include patient-level covariates.

The methods proposed in this work, clearly outperform the traditional naïve method of meta-analysis of haplotypes, which simply consists of contrasting each haplotype against the remaining ones. This is expected to be more profound, especially as the number of possible haplotypes increases, increasing also the type I error rate due to multiple comparisons $[59,60]$. Collapsing the haplotypes and performing a univariate analysis, may potentially be more powerful in several situations [61]. However, in genetic association studies, even though we are interested in small genetic effects we are also concerned about the probability of false findings $[106,107]$. Thus, the multivariate methodology seems to be a reliable alternative.

\section{Conclusions}

We presented multivariate methods that use summarybased data as well as methods that use binary and count data in a generalized linear mixed model framework (logistic regression, multinomial regression and Poisson regression). The methods presented here are easily implemented using standard software such as Stata, R or SAS making them easy to be applied even by nonexperts. In the Additional file 1, Stata code for fitting the models described in this work is given and we expect that these methods will be widely used in the future.

\section{Additional material}

Additional file 1: Stata code for fitting the methods described in the manuscript. The commands should be run within a Stata do-file. 


\section{Acknowledgements}

The author would like to thank the two anonymous reviewers for their valuable comments that improved the quality of the manuscript.

\section{Authors' contributions}

PGB conceived the study, performed the analyses and wrote the manuscript.

Received: 1 July 2010 Accepted: 19 January 2011

Published: 19 January 2011

\section{References}

1. Hirschhorn JN, Lohmueller K, Byrne E, Hirschhorn K: A comprehensive review of genetic association studies. Genet Med 2002, 4(2):45-61.

2. Becker KG, Barnes KC, Bright TJ, Wang SA: The genetic association database. Nat Genet 2004, 36(5):431-432.

3. Normand SL: Meta-analysis: formulating, evaluating, combining, and reporting. Stat Med 1999, 18(3):321-359.

4. Petiti DB: Meta-analysis Decision Analysis and Cost-Effectiveness Analysis. Oxford University Press; 199424

5. Trikalinos TA, Salanti G, Zintzaras E, loannidis JP: Meta-analysis methods. Adv Genet 2008, 60:311-334.

6. Glass G: Primary, secondary and meta-analysis of research. Educ Res 1976, 5:3-8.

7. Greenland S: Meta-analysis. In Modern Epidemiology. Edited by: Rothman KJ, Greenland S. Lippincott Williams 1998:643-673.

8. Chalmers TC, Berrier J, Sacks HS, Levin H, Reitman D, Nagalingam R: Metaanalysis of clinical trials as a scientific discipline. II: Replicate variability and comparison of studies that agree and disagree. Stat Med 1987, 6(7):733-744.

9. Sacks HS, Berrier J, Reitman D, Ancona-Berk VA, Chalmers TC: Meta-analyses of randomized controlled trials. N Engl J Med 1987, 316(8):450-455.

10. Stroup DF, Berlin JA, Morton SC, Olkin I, Williamson GD, Rennie D, Moher D, Becker BJ, Sipe TA, Thacker SB: Meta-analysis of observational studies in epidemiology: a proposal for reporting. Meta-analysis Of Observational Studies in Epidemiology (MOOSE) group. Jama 2000, 283(15):2008-2012.

11. Salanti G, Higgins JP, Trikalinos TA, loannidis JP: Bayesian meta-analysis and meta-regression for gene-disease associations and deviations from Hardy-Weinberg equilibrium. Stat Med 2007, 26(3):553-567.

12. Bagos PG: A unification of multivariate methods for meta-analysis of genetic association studies. Stat Appl Genet Mol Biol 2008, 7, Article31.

13. Thakkinstian A, McElduff P, D'Este C, Duffy D, Attia J: A method for metaanalysis of molecular association studies. Stat Med 2005, 24(9):1291-1306.

14. Minelli C, Thompson JR, Abrams KR, Thakkinstian A, Attia J: The choice of a genetic model in the meta-analysis of molecular association studies. Int J Epidemiol 2005, 34(6):1319-1328.

15. Minelli C, Thompson JR, Tobin MD, Abrams KR: An integrated approach to the meta-analysis of genetic association studies using Mendelian randomization. Am J Epidemiol 2004, 160(5):445-452

16. Bagos PG, Nikolopoulos GK: A method for meta-analysis of case-control genetic association studies using logistic regression. Stat Appl Genet Mol Biol 2007, 6, Article17.

17. Salanti $G$, Higgins JP: Meta-analysis of genetic association studies under different inheritance models using data reported as merged genotypes. Stat Med 2008, 27(5):764-777.

18. Salanti G, Higgins JP, White IR: Bayesian synthesis of epidemiological evidence with different combinations of exposure groups: application to a gene-gene-environment interaction. Stat Med 2006, 25(24):4147-4163.

19. Zondervan KT, Cardon LR: The complex interplay among factors that influence allelic association. Nat Rev Genet 2004, 5(2):89-100.

20. Kaplan N, Morris R: Issues concerning association studies for fine mapping a susceptibility gene for a complex disease. Genet Epidemiol 2001, 20(4):432-457.

21. Liu N, Zhang K, Zhao H: Haplotype-association analysis. Adv Genet 2008, 60:335-405.

22. Schaid DJ: Evaluating associations of haplotypes with traits. Genet Epidemiol 2004, 27(4):348-364.

23. Clark AG: The role of haplotypes in candidate gene studies. Genet Epidemiol 2004, 27(4):321-333.

24. Morris RW, Kaplan NL: On the advantage of haplotype analysis in the presence of multiple disease susceptibility alleles. Genet Epidemiol 2002, 23(3):221-233.
25. Akey J, Jin L, Xiong M: Haplotypes vs single marker linkage disequilibrium tests: what do we gain? Eur J Hum Genet 2001, 9(4):291-300.

26. Levenstien MA, Ott J, Gordon D: Are molecular haplotypes worth the time and expense? A cost-effective method for applying molecular haplotypes. PLoS Genet 2006, 2(8):e127.

27. Marchini J, Cutler D, Patterson N, Stephens M, Eskin E, Halperin E, Lin S, Qin ZS, Munro HM, Abecasis GR, et al: A comparison of phasing algorithms for trios and unrelated individuals. Am J Hum Genet 2006, 78(3):437-450.

28. Xu H, Wu X, Spitz MR, Shete S: Comparison of haplotype inference methods using genotypic data from unrelated individuals. Hum Hered 2004, 58(2):63-68.

29. Niu T: Algorithms for inferring haplotypes. Genet Epidemiol 2004, 27(4):334-347.

30. Lin DY, Huang BE: The use of inferred haplotypes in downstream analyses. Am J Hum Genet 2007, 80(3):577-579.

31. HapMap: The International HapMap Project. Nature 2003, 426(6968):789-796.

32. Attia J, Thakkinstian A, D'Este C: Meta-analyses of molecular association studies: methodologic lessons for genetic epidemiology. I Clin Epidemiol 2003, 56(4):297-303.

33. Thompson SG, Sharp SJ: Explaining heterogeneity in meta-analysis: a comparison of methods. Stat Med 1999, 18(20):2693-2708.

34. Higgins JP, Whitehead A: Borrowing strength from external trials in a meta-analysis. Stat Med 1996, 15(24):2733-2749.

35. Higgins JP, Whitehead A, Turner RM, Omar RZ, Thompson SG: Metaanalysis of continuous outcome data from individual patients. Stat Med 2001, 20(15):2219-2241.

36. Turner RM, Omar RZ, Yang M, Goldstein H, Thompson SG: A multilevel model framework for meta-analysis of clinical trials with binary outcomes. Stat Med 2000, 19(24):3417-3432.

37. van Houwelingen $H C$, Arends $L R$, Stijnen $T$ : Advanced methods in metaanalysis: multivariate approach and meta-regression. Stat Med 2002 21(4):589-624.

38. Wallenstein S, Hodge SE, Weston A: Logistic regression model for analyzing extended haplotype data. Genet Epidemiol 1998, 15(2):173-181.

39. McCullagh P, Nelder JA: Generalized Linear Models. London: Chapman \& Hall; 1989.

40. Chen YH, Kao JT: Multinomial logistic regression approach to haplotype association analysis in population-based case-control studies. BMC Genet 2006, 7:43.

41. Haber M: Log-Linear Models for Linked Loci. Biometrics 1984, 40(1):189-198

42. Weir BS, Wilson SR: Log-linear models for linked loci. Biometrics 1986 , 42(3):665-670.

43. Tiret L, Amouyel P, Rakotovao R, Cambien F, Ducimetiere P: Testing for association between disease and linked marker loci: a log-linear-model analysis. Am J Hum Genet 1991, 48(5):926-934.

44. Mander AP: Haplotype analysis in population-based association studies. The Stata Journal 2001, 1(1):58-75.

45. Agresti A: Categorical Data Analysis. John Wiley \& Sons; 22002.

46. Chen HY: A note on the prospective analysis of outcome-dependent samples. J Roy Soc B 2003, 65(2):575-584.

47. Prentice RL, Pyke R: Logistic disease incidence models and case-control studies. Biometrika 1979, 66(3):403-411.

48. Umbach DM, Weinberg CR: Designing and analysing case-control studies to exploit independence of genotype and exposure. Stat Med 1997, 16(15):1731-1743.

49. French B, Lumley T, Monks SA, Rice KM, Hindorff LA, Reiner AP, Psaty BM: Simple estimates of haplotype relative risks in case-control data. Genet Epidemiol 2006, 30(6):485-494

50. Zaykin DV, Westfall PH, Young SS, Karnoub MA, Wagner MJ, Ehm MG: Testing association of statistically inferred haplotypes with discrete and continuous traits in samples of unrelated individuals. Hum Hered 2002, 53(2):79-91.

51. Schaid DJ, Rowland CM, Tines DE, Jacobson RM, Poland GA: Score tests for association between traits and haplotypes when linkage phase is ambiguous. Am J Hum Genet 2002, 70(2):425-434.

52. Epstein MP, Satten GA: Inference on haplotype effects in case-control studies using unphased genotype data. Am J Hum Genet 2003, 73(6):1316-1329 
53. Chen X, Li Z: Inference of haplotype effects in case-control studies using unphased genotype and environmental data. Biom J 2008, 50(2):270-282

54. Satten GA, Epstein MP: Comparison of prospective and retrospective methods for haplotype inference in case-control studies. Genet Epidemiol 2004, 27(3):192-201.

55. Thomas A: Characterizing allelic associations from unphased diploid data by graphical modeling. Genet Epidemiol 2005, 29(1):23-35.

56. Baker SG: A simple loglinear model for haplotype effects in a casecontrol study involving two unphased genotypes. Stat Appl Genet Mol Biol 2005, 4, Article14.

57. Lin DY, Zeng D, Millikan R: Maximum likelihood estimation of haplotype effects and haplotype-environment interactions in association studies. Genet Epidemiol 2005, 29(4):299-312.

58. DerSimonian R, Laird N: Meta-analysis in clinical trials. Controlled Clinical Trials 1986, 7:177-188.

59. Becker T, Cichon S, Jonson E, Knapp M: Multiple testing in the context of haplotype analysis revisited: application to case-control data. Ann Hum Genet 2005, 69(Pt 6):747-756.

60. Becker T, Knapp M: A powerful strategy to account for multiple testing in the context of haplotype analysis. Am J Hum Genet 2004, 75(4):561-570.

61. Matthews AG, Haynes C, Liu C, Ott J: Collapsing SNP genotypes in casecontrol genome-wide association studies increases the type I error rate and power. Stat Appl Genet Mol Biol 2008, 7(1), Article23.

62. Berkey CS, Hoaglin DC, Antczak-Bouckoms A, Mosteller F, Colditz GA: Metaanalysis of multiple outcomes by regression with random effects. Stat Med 1998, 17(22):2537-2550.

63. White IR: Multivariate random-effects meta-analysis. Stata Journal 2009, 9:40-56.

64. Jackson D, White IR, Thompson SG: Extending DerSimonian and Laird's methodology to perform multivariate random effects meta-analyses. Stat Med 29(12):1282-1297.

65. Judge GG, Griffiths WE, Hill RC, Lutkepohl H, Lee T-C: The Theory and Practice of Econometrics. New York: John Wiley \& Sons; 21985.

66. Berndt SI, Potter JD, Hazra A, Yeager M, Thomas G, Makar KW, Welch R, Cross AJ, Huang WY, Schoen RE, et al: Pooled analysis of genetic variation at chromosome 8q24 and colorectal neoplasia risk. Hum Mol Genet 2008, 17(17):2665-2672.

67. Setiawan WW, Doherty JA, Shu XO, Akbari MR, Chen C, De Vivo I, Demichele A, Garcia-Closas M, Goodman MT, Haiman CA, et al: Two estrogen-related variants in CYP19A1 and endometrial cancer risk: a pooled analysis in the Epidemiology of Endometrial Cancer Consortium. Cancer Epidemiol Biomarkers Prev 2009, 18(1):242-247.

68. Lambrechts D, Storkebaum E, Morimoto M, Del-Favero J, Desmet F, Marklund SL, Wyns S, Thijs V, Andersson J, van Marion I, et al: VEGF is a modifier of amyotrophic lateral sclerosis in mice and humans and protects motoneurons against ischemic death. Nat Genet 2003, 34(4):383-394

69. Uitterlinden AG, Ralston SH, Brandi ML, Carey AH, Grinberg D, Langdahl BL, Lips P, Lorenc R, Obermayer-Pietsch B, Reeve J, et al: The association between common vitamin $D$ receptor gene variations and osteoporosis: a participant-level meta-analysis. Ann Intern Med 2006, 145(4):255-264.

70. Higgins JP, Thompson SG, Deeks JJ, Altman DG: Measuring inconsistency in meta-analyses. Bmj 2003, 327(7414):557-560.

71. Skrondal A, Rabe-Hesketh S: Multilevel logistic regression for polytomous data and rankings. Psychometrika 2003, 68(2):267-287.

72. Mickey RM, Elashoff R: A generalization of the Mantel-Haenszel estimator of partial association for $2 \times \mathrm{J} \times \mathrm{K}$ tables. Biometrics 1985, 41(3):623-635.

73. Heyman ER, Koch GG: Average Partial Association in Three-Way Contingency Tables: A Review and Discussion of Alternative Tests. International Statistical Review 1978, 46:237-254.

74. Darroch JN: Interactions in multifactor contingency tables. J Roy Statist Soc B 1962, 24(1):251-263.

75. Berrington ADG, Cox DR: Interpretation of interaction: A review. Ann App/ Stat 2007, 1(2):371-385

76. Mickey RM: Assessment of three way interaction in $2 \times \mathrm{J} \times \mathrm{K}$ tables. Computational Statistics \& Data Analysis 1987, 5(1):23-30.

77. Zintzaras E, Koufakis T, Ziakas PD, Rodopoulou P, Giannouli S, Voulgarelis M: A meta-analysis of genotypes and haplotypes of methylenetetrahydrofolate reductase gene polymorphisms in acute lymphoblastic leukemia. Eur J Epidemiol 2006, 21(7):501-510.
78. Thakkinstian A, D'Este C, Attia J: Haplotype analysis of VDR gene polymorphisms: a meta-analysis. Osteoporos Int 2004, 15(9):729-734.

79. Lu G, Ades AE: Combination of direct and indirect evidence in mixed treatment comparisons. Stat Med 2004, 23(20):3105-3124.

80. Minelli C, Thompson JR, Abrams KR, Lambert PC: Bayesian implementation of a genetic model-free approach to the meta-analysis of genetic association studies. Stat Med 2005, 24(24):3845-3861.

81. Riley RD, Abrams KR, Lambert PC, Sutton AJ, Thompson JR: An evaluation of bivariate random-effects meta-analysis for the joint synthesis of two correlated outcomes. Stat Med 2007, 26(1):78-97.

82. Riley RD, Abrams KR, Sutton AJ, Lambert PC, Thompson JR: Bivariate random-effects meta-analysis and the estimation of between-study correlation. BMC Med Res Methodol 2007, 7:3.

83. Rabe-Hesketh S, Skrondal A, Pickles A: Reliable estimation of generalized linear mixed models using adaptive quadrature. The Stata Journal 2002, 2:1-21.

84. Rabe-Hesketh S, Skrondal A, Pickles A: Maximum likelihood estimation of limited and discrete dependent variable models with nested random effects. Journal of Econometrics 2005, 128(2):301-323.

85. Ioannidis JP, Ntzani EE, Trikalinos TA: 'Racial' differences in genetic effects for complex diseases. Nat Genet 2004, 36(12):1312-1318.

86. Ioannidis JP, Ntzani EE, Trikalinos TA, Contopoulos-loannidis DG: Replication validity of genetic association studies. Nat Genet 2001, 29(3):306-309.

87. Ioannidis JP, Trikalinos TA: Early extreme contradictory estimates may appear in published research: the Proteus phenomenon in molecular genetics research and randomized trials. J Clin Epidemiol 2005, 58(6):543-549.

88. Ioannidis JP, Trikalinos TA, Ntzani EE, Contopoulos-loannidis DG: Genetic associations in large versus small studies: an empirical assessment. Lancet 2003, 361(9357):567-571.

89. Trikalinos TA, Ntzani EE, Contopoulos-loannidis DG, loannidis JP: Establishment of genetic associations for complex diseases is independent of early study findings. Eur J Hum Genet 2004, 12(9):762-769.

90. Danforth KN, Hayes RB, Rodriguez C, Yu K, Sakoda LC, Huang WY, Chen BE, Chen J, Andriole GL, Calle EE, et al: Polymorphic variants in PTGS2 and prostate cancer risk: results from two large nested case-control studies. Carcinogenesis 2008, 29(3):568-572.

91. Danforth KN, Rodriguez C, Hayes RB, Sakoda LC, Huang WY, Yu K, Calle EE, Jacobs EJ, Chen BE, Andriole GL, et al: TNF polymorphisms and prostate cancer risk. Prostate 2008, 68(4):400-407.

92. Sareneva I, Koskinen LL, Korponay-Szabo IR, Kaukinen K, Kurppa K, Ziberna F, Vatta S, Not T, Ventura A, Adany R, et al: Linkage and association study of FcgammaR polymorphisms in celiac disease. Tissue Antigens 2009, 73(1):54-58.

93. Kedda MA, Duffy DL, Bradley B, O'Hehir RE, Thompson PJ: ADAM33 haplotypes are associated with asthma in a large Australian population. Eur J Hum Genet 2006, 14(9):1027-1036.

94. Kavvoura FK, Akamizu T, Awata T, Ban Y, Chistiakov DA, Frydecka I, Ghaderi A, Gough SC, Hiromatsu Y, Ploski R, et al: Cytotoxic T-lymphocyte associated antigen 4 gene polymorphisms and autoimmune thyroid disease: a meta-analysis. J Clin Endocrinol Metab 2007, 92(8):3162-3170.

95. Kehoe PG, Katzov H, Feuk L, Bennet AM, Johansson B, Wiman B, de Faire U, Cairns NJ, Wilcock GK, Brookes AJ, et al: Haplotypes extending across ACE are associated with Alzheimer's disease. Hum Mol Genet 2003, 12(8):859-867.

96. Ma J, Qin W, Wang XY, Guo TW, Bian L, Duan SW, Li XW, Zou FG, Fang YR, Fang JX, et al: Further evidence for the association between G72/G30 genes and schizophrenia in two ethnically distinct populations. Mol Psychiatry 2006, 11(5):479-487.

97. Tsuchiya T, Schwarz PE, Bosque-Plata LD, Geoffrey Hayes M, Dina C, Froguel P, Wayne Towers G, Fischer S, Temelkova-Kurktschiev T, Rietzsch H, et al: Association of the calpain-10 gene with type 2 diabetes in Europeans: results of pooled and meta-analyses. Mol Genet Metab 2006, 89(1-2):174-184.

98. Hollis-Moffatt JE, Rowley KA, Phipps-Green AJ, Merriman ME, Dalbeth N, Gow P, Harrison AA, Highton J, Jones PB, Stamp LK, et al: The ITGAV rs3738919 variant and susceptibility to rheumatoid arthritis in four Caucasian sample sets. Arthritis Res Ther 2009, 11(5):R152.

99. Apostolakis S, Amanatidou V, Papadakis EG, Spandidos DA: Genetic diversity of $\mathrm{CX} 3 \mathrm{CR} 1$ gene and coronary artery disease: new insights through a meta-analysis. Atherosclerosis 2009, 207(1):8-15. 
100. Song Y, Niu T, Manson JE, Kwiatkowski DJ, Liu S: Are variants in the CAPN10 gene related to risk of type 2 diabetes? A quantitative assessment of population and family-based association studies. Am J Hum Genet 2004, 74(2):208-222.

101. Berkey CS, Hoaglin DC, Mosteller F, Colditz GA: A random-effects regression model for meta-analysis. Stat Med 1995, 14(4):395-411.

102. Thompson SG, Turner RM, Warn DE: Multilevel models for meta-analysis, and their application to absolute risk differences. Stat Methods Med Res 2001, 10(6):375-392.

103. van Houwelingen $\mathrm{HC}$, Zwinderman $\mathrm{KH}$, Stijnen $\mathrm{T}$ : A bivariate approach to meta-analysis. Stat Med 1993, 12(24):2273-2284.

104. Fiocco M, Putter $H$, van Houwelingen JC: Meta-analysis of pairs of survival curves under heterogeneity: a Poisson correlated gamma-frailty approach. Stat Med 2009, 28(30):3782-3797.

105. Bagos PG, Nikolopoulos GK: Mixed-effects poisson regression models for meta-analysis of follow-up studies with constant or varying durations. International Journal of Biostatistics 2009, 5, Article21.

106. Ioannidis JP: Genetic associations: false or true? Trends Mol Med 2003, 9(4):135-138.

107. Ioannidis JP: Why most published research findings are false. PLOS Med 2005, 2(8):e124.

108. Weston A, Pan CF, Ksieski HB, Wallenstein S, Berkowitz GS, Tartter PI, Bleiweiss IJ, Brower ST, Senie RT, Wolff MS: p53 haplotype determination in breast cancer. Cancer Epidemiol Biomarkers Prev 1997, 6(2):105-112.

109. Nunokawa A, Watanabe $Y$, Kaneko N, Sugai T, Yazaki S, Arinami T, Ujike H, Inada $T$, Iwata N, Kunugi $H$, et al: The dopamine D3 receptor (DRD3) gene and risk of schizophrenia: case-control studies and an updated metaanalysis. Schizophr Res 2010, 116(1):61-67.

110. Moxley G, Meulenbelt I, Chapman K, van Diujn CM, Eline Slagboom P, Neale MC, Smith AJ, Carr AJ, Loughlin J: Interleukin-1 region meta-analysis with osteoarthritis phenotypes. Osteoarthritis Cartilage 2010, 18(2):200-207.

111. Evangelou E, Chapman K, Meulenbelt I, Karassa FB, Loughlin J, Carr A, Doherty M, Doherty S, Gomez-Reino JJ, Gonzalez A, et al: Large-scale analysis of association between GDF5 and FRZB variants and osteoarthritis of the hip, knee, and hand. Arthritis Rheum 2009, 60(6):1710-1721.

112. Zintzaras E, Rodopoulou P, Sakellaridis N: Variants of the arachidonate 5lipoxygenase-activating protein (ALOX5AP) gene and risk of stroke: a HuGE gene-disease association review and meta-analysis. Am J Epidemiol 2009, 169(5):523-532.

113. Auburn S, Diakite M, Fry AE, Ghansah A, Campino S, Richardson A, Jallow M, Sisay-Joof F, Pinder M, Griffiths MJ, et al: Association of the GNAS locus with severe malaria. Hum Genet 2008, 124(5):499-506.

114. Shi J, Badner JA, Liu C: PDLIM5 and susceptibility to bipolar disorder: a family-based association study and meta-analysis. Psychiatr Genet 2008, 18(3):116-121.

115. Bevan S, Dichgans M, Gschwendtner A, Kuhlenbaumer G, Ringelstein EB, Markus HS: Variation in the PDE4D gene and ischemic stroke risk: a systematic review and meta-analysis on 5200 cases and 6600 controls. Stroke 2008, 39(7):1966-1971.

116. Thakkinstian A, Dmitrienko S, Gerbase-Delima M, McDaniel DO, Inigo P, Chow KM, McEvoy M, Ingsathit A, Trevillian P, Barber WH, et al: Association between cytokine gene polymorphisms and outcomes in renal transplantation: a meta-analysis of individual patient data. Nephrol Dial Transplant 2008, 23(9):3017-3023.

117. Schunkert $H$, Gotz A, Braund $P$, McGinnis R, Tregouet DA, Mangino M, Linsel-Nitschke P, Cambien F, Hengstenberg C, Stark K, et al: Repeated replication and a prospective meta-analysis of the association between chromosome 9p21.3 and coronary artery disease. Circulation 2008, 117(13):1675-1684

118. Castano-Rodriguez N, Diaz-Gallo LM, Pineda-Tamayo R, Rojas-Villarraga A, Anaya JM: Meta-analysis of HLA-DRB1 and HLA-DQB1 polymorphisms in Latin American patients with systemic lupus erythematosus. Autoimmun Rev 2008, 7(4):322-330.

119. Lyon HN, Florez JC, Bersaglieri T, Saxena R, Winckler W, Almgren P, Lindblad U, Tuomi T, Gaudet D, Zhu X, et al: Common variants in the ENPP1 gene are not reproducibly associated with diabetes or obesity. Diabetes 2006, 55(11):3180-3184.

120. Li D, Collier DA, He L: Meta-analysis shows strong positive association of the neuregulin 1 (NRG1) gene with schizophrenia. Hum Mol Genet 2006, 15(12):1995-2002.
121. Talkowski ME, Seltman H, Bassett AS, Brzustowicz LM, Chen X, Chowdari KV, Collier DA, Cordeiro Q, Corvin AP, Deshpande SN, et al: Evaluation of a susceptibility gene for schizophrenia: genotype based meta-analysis of RGS4 polymorphisms from thirteen independent samples. Biol Psychiatry 2006, 60(2):152-162.

122. Thakkinstian A, McEvoy M, Minelli C, Gibson P, Hancox B, Duffy D, Thompson J, Hall I, Kaufman J, Leung TF, et al: Systematic review and meta-analysis of the association between \{beta\}2-adrenoceptor polymorphisms and asthma: a HuGE review. Am J Epidemiol 2005 162(3):201-211.

123. loannidis JP, Ralston SH, Bennett ST, Brandi ML, Grinberg D, Karassa FB, Langdahl B, van Meurs JB, Mosekilde L, Scollen S, et al: Differential genetic effects of ESR1 gene polymorphisms on osteoporosis outcomes. JAMA 2004, 292(17):2105-2114.

124. Johansson M, McKay JD, Wiklund F, Rinaldi S, Verheus M, van Gils $C H$, Hallmans G, Balter K, Adami HO, Gronberg H, et al: Implications for prostate cancer of insulin-like growth factor-I (IGF-I) genetic variation and circulating IGF-I levels. J Clin Endocrinol Metab 2007, 92(12):4820-4826.

125. De Gaetano M, Quacquaruccio G, Pezzini A, Latella MC, A DIC, Del Zotto E, Padovani A, Lichy C, Grond-Ginsbach C, Gattone M, et al: Tissue factor gene polymorphisms and haplotypes and the risk of ischemic vascular events: four studies and a meta-analysis. J Thromb Haemost 2009, 7(9):1465-1471.

126. Orozco G, Abelson AK, Gonzalez-Gay MA, Balsa A, Pascual-Salcedo D, Garcia A, Fernandez-Gutierrez B, Petersson I, Pons-Estel B, Eimon A, et al: Study of functional variants of the BANK1 gene in rheumatoid arthritis. Arthritis Rheum 2009, 60(2):372-379.

127. Brunner EJ, Kivimaki M, Witte DR, Lawlor DA, Davey Smith G, Cooper JA, Miller M, Lowe GD, Rumley A, Casas JP, et al: Inflammation, insulin resistance, and diabetes-Mendelian randomization using CRP haplotypes points upstream. PLoS Med 2008, 5(8):e155.

128. Lee KM, Kang D, Clapper ML, Ingelman-Sundberg M, Ono-Kihara M, Kiyohara C, Min S, Lan Q, Le Marchand L, Lin P, et al: CYP1A1, GSTM1, and GSTT1 polymorphisms, smoking, and lung cancer risk in a pooled analysis among Asian populations. Cancer Epidemiol Biomarkers Prev 2008, 17(5):1120-1126.

129. McGrath M, Lee IM, Hankinson SE, Kraft P, Hunter DJ, Buring J, De Vivo I: Androgen receptor polymorphisms and endometrial cancer risk. Int J Cancer 2006, 118(5):1261-1268.

130. Huang WY, Olshan AF, Schwartz SM, Berndt SI, Chen C, Llaca V, Chanock SJ, Fraumeni JF Jr, Hayes RB: Selected genetic polymorphisms in MGMT, XRCC1, XPD, and XRCC3 and risk of head and neck cancer: a pooled analysis. Cancer Epidemiol Biomarkers Prev 2005, 14(7):1747-1753.

131. Maraganore DM, de Andrade M, Elbaz A, Farrer MJ, loannidis JP, Kruger R, Rocca WA, Schneider NK, Lesnick TG, Lincoln SJ, et al: Collaborative analysis of alpha-synuclein gene promoter variability and Parkinson disease. JAMA 2006, 296(6):661-670.

doi:10.1186/1471-2156-12-8

Cite this article as: Bagos: Meta-analysis of haplotype-association studies: comparison of methods and empirical evaluation of the literature. BMC Genetics 2011 12:8.

\section{Submit your next manuscript to BioMed Central and take full advantage of:}

- Convenient online submission

- Thorough peer review

- No space constraints or color figure charges

- Immediate publication on acceptance

- Inclusion in PubMed, CAS, Scopus and Google Scholar

- Research which is freely available for redistribution

Submit your manuscript at www.biomedcentral.com/submit
C Biomed Central 